\title{
Numerical Modeling of Fluid Flow in the Tape Casting Process
}

\author{
Jabbari, Masoud; Hattel, Jesper Henri
}

Published in:

AIP Conference Proceedings - American Institute of Physics

Link to article, DOI:

$10.1063 / 1.3636690$

Publication date:

2011

Document Version

Publisher's PDF, also known as Version of record

Link back to DTU Orbit

Citation (APA):

Jabbari, M., \& Hattel, J. H. (2011). Numerical Modeling of Fluid Flow in the Tape Casting Process. AIP Conference Proceedings - American Institute of Physics, 1389(1), 143-146. https://doi.org/10.1063/1.3636690

\section{General rights}

Copyright and moral rights for the publications made accessible in the public portal are retained by the authors and/or other copyright owners and it is a condition of accessing publications that users recognise and abide by the legal requirements associated with these rights.

- Users may download and print one copy of any publication from the public portal for the purpose of private study or research.

- You may not further distribute the material or use it for any profit-making activity or commercial gain

- You may freely distribute the URL identifying the publication in the public portal

If you believe that this document breaches copyright please contact us providing details, and we will remove access to the work immediately and investigate your claim. 


\title{
Numerical Modeling of Fluid Flow in the Tape Casting Process
}

\author{
Masoud Jabbari and Jesper Hattel \\ Department of Mechanical Engineering, Technical University of Denmark, Nils Koppels Allé, 2800 Kgs. Lyngby, \\ Denmark.
}

\begin{abstract}
The flow behavior of the fluid in the tape casting process is analyzed. A simple geometry is assumed for running the numerical calculations in ANSYS Fluent and the main parameters are expressed in non-dimensional form. The effect of different values for substrate velocity and pressure force on the flow pattern as well as resultant tape thickness is evaluated. The analysis deals with the case of parallel blades and focuses on the ratio between the present hydrostatic pressure and the magnitude of the viscous force. A new non-dimensional height for the tape thickness is proposed and the effect of the substrate velocity is evaluated. The results of the modeling show that a relatively uniform tape thickness can be achieved. Moreover, the results are compared with selected experimental and analytical data from literature and good agreement is found.
\end{abstract}

Keywords: Tape casting, non-dimensional parameters, substrate velocity, tape thickness. PACS: 47.11.Df

\section{INTRODUCTION}

Tape casting is a well-established technique used for large-scale fabrication of ceramic substrates and multilayered structures [1]. In this method the ceramic slurry which is mixed with binders, plasticizers and dispersants, is pumped into a ceramic container and is then conveyed through the doctor blade to the drying step. The general principle of the process is illustrated in Figure 1. The parallel (doctor) blade process was first used in preparing ceramic tapes in the 1940s and it has a key role in producing thin and flat ceramic tapes [2;3]. Tapes which are formed by tape casting are generally thin, ranging from a few microns to a few millimeters. The thickness is of critical importance in tape casting, since it affects the final properties of the tape. Different parameters such as powder distribution, slurry composition, flow field, sintering and etc. affect the thickness of final tape [4-6]. Moreover, the geometry of the process itself has different effects on the related final properties of final product [7].

In general, the fluid flow in the doctor blade region and the subsequent outflow can be modelled using NavierStokes equations in two dimensions realizing that the flow is generated by the viscous drag due to the peeling velocity of the substrate as well as the static hydraulic pressure in the slurry reservoir. There are a few research papers in which the flow field and the resulting tape thickness were modeled analytically. Chou et al. [4] modeled the flow in the parallel blade region. Because of the low Reynolds number, they neglect the inertia forces hence assuming Newtonian-Stokes flow.

In a general sense, fluids that exhibit characteristics not predicted by the Newtonian constitutive equations are non-Newtonian. The exceptions to the classical Newtonian fluids are not of rare occurrence, and in fact many common fluids are non-Newtonian. Figure 2 shows the rheological classification of the non-Newtonian fluids. The Bingham constitutive was used by Guangneng Zhang et al. [8] to model the flow in the tape casting process. The Bingham formulation represents a linear relation between shear stress and shear rate like for Newtonian fluids, but also combines with a yield stress threshold for flow. However this model is not realistic enough for most slurries. Pitchumani and Karbhari [9] evaluated the effects of an imposed pressure gradient due to the height of the slurry in the casting head, as well as those of the drag due to the moving substrate on the slurry flow, by modeling the slurry discharge as a generalized planar Couette flow. Many difficulties are encountered when predicting non-Newtonian flow. This is mainly due to the theoretical predictions usually being based upon idealized rheological fluid properties with associated constitutive equations that are often difficult to verify under conditions of complex flows. An example of numerical modeling of the tape casting process was carried out by Loest et al. [10] using the finite 
element method (FEM). Their work was mainly focused on the flow entry in the reservoir to evaluate the vortices. Also, pressure-driven flow was neglected since they used a narrow range of casting conditions.

The purpose of the present investigation is to numerically model the fluid flow in the tape casting process using the finite volume method (FVM) in the commercial software ANSYS Fluent. As a very coarse simplification for this preliminary analysis, liquid water is used as a model fluid under the assumption of an incompressible and Newtonian slurry. A very simple L-shape geometry was used to carry out the modeling. In real tape casting the exit height of the blade and the final height of the wet tape are in the range of millimeters. Moreover, the height of the slurry and the dimensions of the tape caster in general are in the range of centimeters. So, in order to avoid an extremely fine mesh in the doctor blade region the scales which are used in the model are in the range of centimeters. But, for generalizing the model, all parameters are used in non-dimensional form. Both pressure gradient and drag forces were implemented in the model. The numerical model calculates the flow in the container and the doctor blade region, so the tape thickness which goes out of the doctor blade is consequently determined on the basis of the continuity equation (mass balance). The model was compared with analytical and experimental results from the literature and good agreement was found.

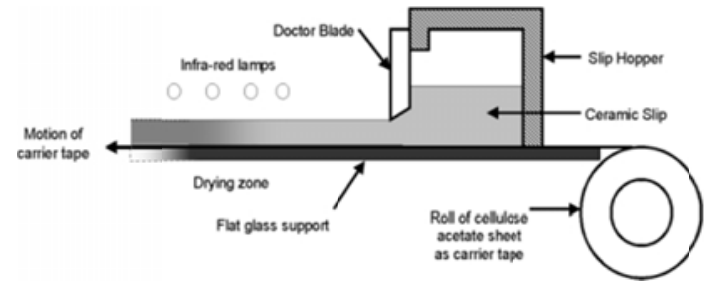

FIGURE 1. Schematic of tape casting process.

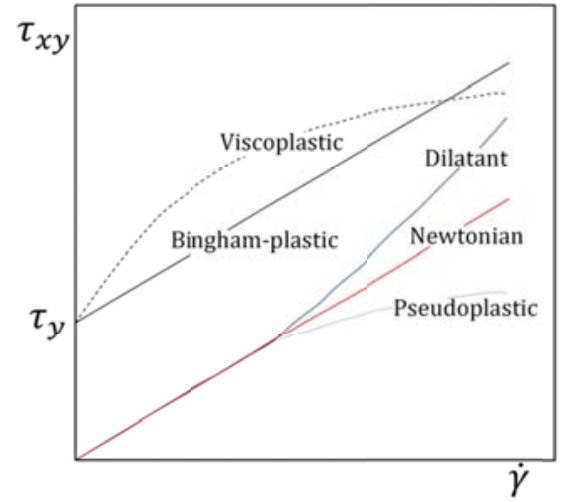

FIGURE 2. Rheological classification of fluids.

\section{MODEL DESCRIPTION}

The slurry movement in the tape casting process can be modeled as both pressure- and shear-driven (Couette) flows. The 2D cross-section of the tape casting geometry which is used in this paper is shown in Figure 3 . The pressure is imposed to the system by the slurry head, $\Delta P=\rho_{s} H_{s} g$, in which $g, \rho_{s}$ and $H_{s}$ are respectively the gravity acceleration, density and height of the slurry. In the case of a continuous process one can assume that the slurry is pumped into the reservoir with a similar rate as the flow leaving the doctor blade region resulting in a constant pressure height.

For an incompressible, Newtonian fluid, and by using a no-slip boundary condition at the walls, the simplified Navier-Stokes equations are solved yielding the expressions below [2]:

$$
\begin{array}{ll}
u_{y}=\frac{\Delta P}{2 \eta L} z\left(H_{d}-z\right) & \text { Pressure-driven flow } \\
u_{y}=U-\frac{U}{H_{d}} z & \text { Shear-driven flow }
\end{array}
$$

where $u_{y}$ is the slurry velocity, $\eta$ is the viscosity, $U$ the casting velocity, and $\Delta P$ is the pressure gradient. For expressing the solution on non-dimensional form which also makes comparing with analytical results from literature straightforward, the following non-dimensional parameters as suggested by Hyun Jun Kim and et al. [2] are introduced:

$$
\Phi=\frac{u_{y}}{U}, \quad \varepsilon=\frac{z}{H_{d}} \quad \text { and } \quad \Pi=\frac{\Delta P H_{d}^{2}}{2 \eta L U}
$$

The sole parameter in this solution which determines the shape of the velocity profiles as well as the wet tape thickness is the ratio of pressure force to viscous force П, As Kim et al. [2] proved. As illustrated in Figure 4, by increasing this ratio the height of the slurry which leaves the doctor blade region (= the thickness of the wet tape) is 
increased. This phenomenon arises from the mass balance and solving the resulting continuity equation which states that the "area" of the velocity profiles the in two regions should be the same $\left(A^{\prime}=A\right)$.

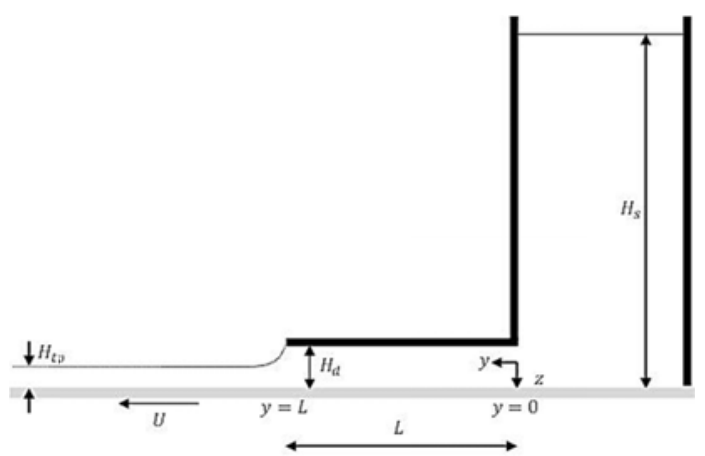

FIGURE 3. Geometry of tape casting used in the analysis.
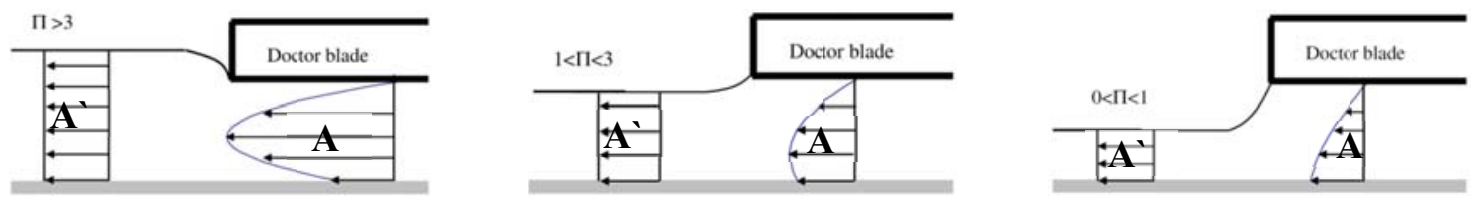

FIGURE 4. Effect of the П parameter on the tape thickness.

\section{RESULTS AND DISSCUSION}

The first output of the numerical simulation is the velocity field in the doctor blade zone. The results for the defined height of doctor blade (here $5 \mathrm{~cm}$ ) show that in the constant hydrostatic pressure condition, decreasing the substrate velocity leads to increase of the viscous forces, and consequently the curvature of the velocity profile increases (as it seen from Figure 5). This phenomenon affects the velocity profile also. On the other hand, increasing the pressure head results in increasing of the area of the velocity profile $(A)$, which can be seen in Figure 6 , and consequently the "area" out of the blade $\left(A^{\prime}\right)$ is increased. On the contrary, increasing the substrate velocity for a constant pressure force, the thickness of tape is decreased in the exit and vice versa. It should also be noted that in the limit of $\Pi \ll 1$, the primarily shear-driven flow has the same velocity and shear stress profile for Newtonian and power-law fluids [2].

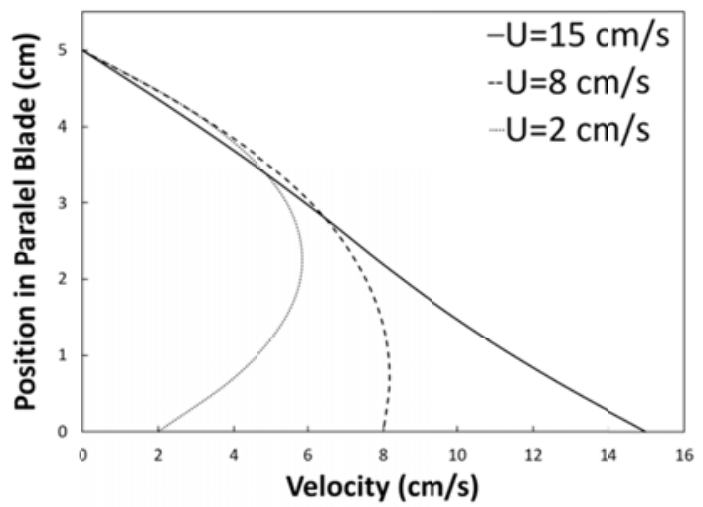

FIGURE 5. Velocity profile in the doctor blade region for different substrate velocities.

The thickness of the wet tape was divided by the height of doctor blade to introduce a new non-dimensional tape thickness $\left(H_{t p} / H_{D}=\Gamma\right)$. The effect of the substrate velocity on the new proposed parameter $(\Gamma)$ was investigated and illustrated in Figure 7. The results show that as the velocity of the substrate becomes high the value of $\Gamma$ 
decreases. This behavior also agrees with the velocity profile evaluation. Specifically it is observed that as the velocity of the substrate reaches a specific threshold, the non-dimensional tape thickness becomes constant. From a process-viewpoint it is important to have a constant substrate velocity to get uniform tape thickness. Thus, to choose a proper velocity in the process, you should avoid being in the first region in Figure $7(\approx 0 \leq U \leq 1)$, since the highest variation in the tape thickness takes place in this area. In addition, the advantage of such a diagram is to have good basics for choosing the substrate velocity. Besides, using a non-dimensional diagram presents another advantage in which, any similar geometry in the tape casting process can be evaluated and estimated to choose a practical substrate velocity.

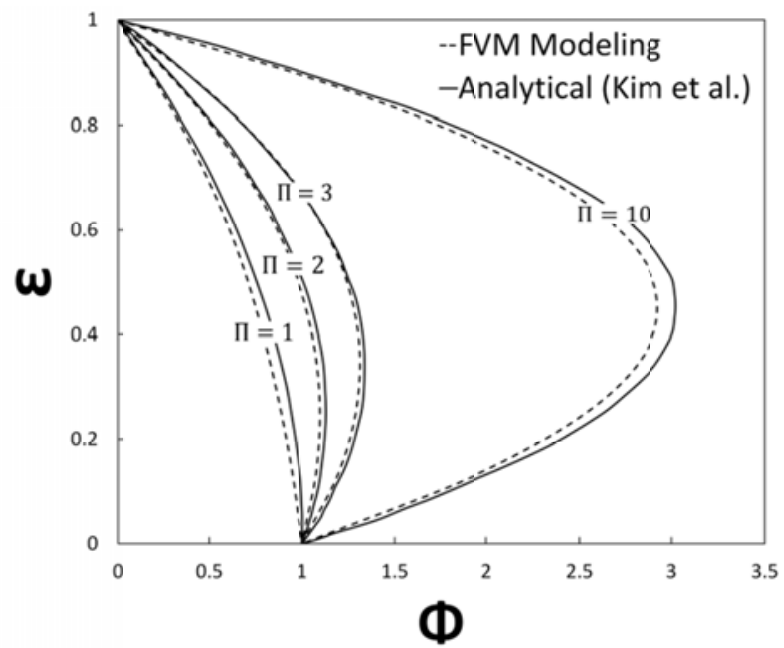

FIGURE 6. The non-dimensional velocity profile in the blade on the basis of different $\Pi$.

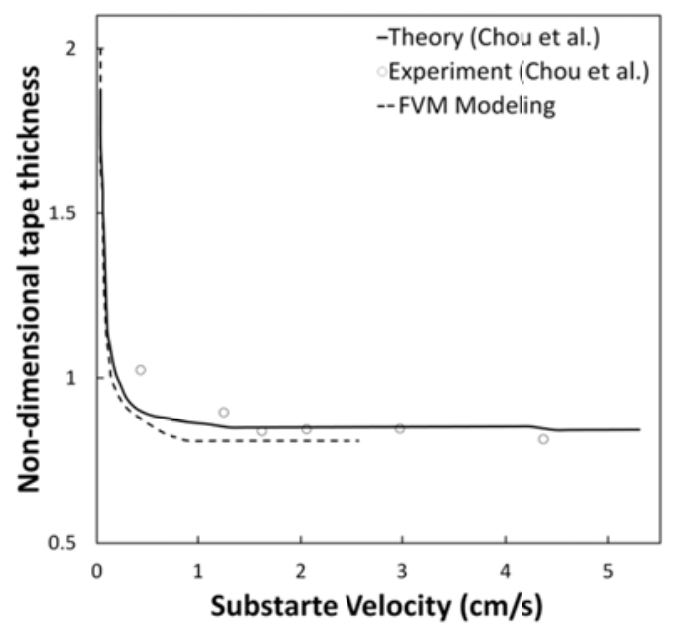

FIGURE 7. Effect of the substrate velocity $(U)$ on the non-dimensional tape thickness $(\Gamma)$.

\section{CONCLUSION}

In the present paper a numerical simulation of the flow for an L-shape tape casting prociess is carried out with the FV based software ANSYS Fluent. Based on the ratio between pressure and viscous forces ( $\Pi$ ), the non-dimensional velocity profile was predicted and compared with the analytical solution from Kim et al [2]. The behavior of the slurry after the blade exit was also discussed as a function of $\Pi$. It is observed that by increasing the value of $\Pi$ (decreasing the substrate velocity) the slurry in the blade exit tends to increase the height of the slurry, thus increasing thickness of the tape. In order have a general parameter in the process to compare with, a new nondimensional term was proposed $(\Gamma)$, which is the ratio of the tape thickness to the height of the blade exit. The effect of substrate velocity on the proposed parameter was evaluated. Results show that by increasing the substrate velocity (decreasing $\Pi$ ) the parameter $\Gamma$ decreases until a certain point, where it reaches a plateau with a relatively constant value.

\section{REFERENCES}

1. D. Hotza, P. Greil., Mater. Sci. Eng. A 202, 206-217 (1995).

2. Hyun Jun Kim, Matthe John M. Krane, Kevin P. Trumble, Keith J. Bowman., J. Am. Ceram. Soc. 89, 2769-2775 (2006).

3. C. Pagnoux, T. Chartier, M.deF. Granja, F. Doreau, J.M. Ferreira, J.F. Baumard., J. Europ. Ceram. Soc. 18, $241-247$ (1998).

4. YE T. CHOU, YA T. Ko, MAN F. YAN, J. Am. Ceram. Soc. 70, 280-282 (1987).

5. Yasuhiro Tanimoto, Tohru Hayakawa, Kimiya Nemoto, Dental Materials 23, 549-555 (2007).

6. Maria P. Albano, Liliana B. Garrido, Ceram. Int. 31, 57-66 (2005).

7. P. H. Gaskell, B. Rand, J. L. Summers, H. M. Thompson, J. Europ. Ceram. Soc. 17, 1185-1192 (1997).

8. Guangneng Zhang, Yonggang Wang, Jusheng Ma, Mater. Sci. Eng. A 337, 274-280 (2002).

9. Rangarajan Pitchumdni, Vistasp M. Karbhari, J. Am. Ceram. Soc. 78, 2497-2503 (1995).

10. Hagen Loest, Roland Lipp, Evan Mitsoulis, J. Am. Ceram. Soc. 77, 254-262 (1994). 